\title{
Experimental substantiation of acoustic method for determination of "coal bed - country rock" contact relations based on boundary inverse problem solution
}

\author{
Vladimir Shkuratnik ${ }^{1}$, Petr Nikolenko ${ }^{1}$, Larisa Nazarova $^{1^{*}}$ and Leonid Nazarov ${ }^{1}$ \\ ${ }^{1}$ Institute of Complex Exploitation of Mineral Resources of the Russian Academy of Sciences, \\ Moscow, Russia.
}

\begin{abstract}
The article describes the acoustic method developed by the authors to determine the contact conditions between coal seam and host rocks on the basis of boundary inverse problem solution. Justification of the applicability of the method is made by means of physical modeling, in which samples from the model material were subjected to step-by-step uniaxial loading with simultaneous ultrasonic sounding using a multichannel scheme. In this case, various friction conditions were set for different samples at the "sample-plate of the press" interface. Based on the results of sounding, the distribution of velocities in the illuminated domain of the sample was reconstructed using tomographic processing. The array of data obtained as a result of acoustic tomography was used as input data to solve the inverse problem. As a result of the solution of the inverse problem, it was shown that the appearance of slip regions at the boundaries of the sample generates tensile stresses, the magnitude of which reaches 0.8 from the axial load. The developed method makes it possible, on the basis of acoustic measurements, to identify areas with a reduced coefficient of friction between the coal seam and the host rocks, the presence of which may be the reason of dangerous dynamic phenomena.
\end{abstract}

\section{Introduction}

Combine excavation of coal is accompanied by a rapid change of stress fields in the rock mass, which sometimes leads to dangerous dynamic phenomena (sudden outbursts of coal and gas, rock burst, etc.) [1,2]. To monitor the state of the coal massif and forecast such phenomena, mines are equipped with microseismic monitoring systems $[3,4,5]$. However, modern methods of interpreting data from seismic observations in mines do not allow to detect heterogeneities in the massif with linear dimensions of several centimeters $[6,8,7$, 9]. Such heterogeneities include also thin contact zones of coal seams with host rocks, and their acoustic properties differ insignificantly [10]. Meanwhile, the presence of areas with reduced coefficient of friction may be one of the reasons for the destruction of the bottomhole part of the seam, followed by the coal and gas bursts [11]. Such arias introduce

\footnotetext{
*Corresponding author: lanazarova@ngs.ru
} 
qualitative changes into the stress-strain state of the coal massif and can be observed by acoustic methods of mine geophysics $[12,13]$.

In the present work, the method for determining contact conditions of a coal seam with host rocks is developed on the results of physical modeling. The method is based on the solution of the inverse boundary problem by seismic tomography data with the use of the empirical dependence of the longitudinal waves velocity on the mean normal stress.

\section{Experimental setup}

An epoxy resin filled with muscovite was used as model material. The content of mica was selected so that the acoustic and deformation characteristics of the resulting composite, as well as its density ( $1600 \mathrm{~kg} / \mathrm{m} 3)$ were close to those for coal.Five cylindrical (diameter 38 $\mathrm{mm}$, height $76 \mathrm{~mm}$ ) and eight rectangular samples were made (length $X=100 \mathrm{~mm}$, height $\mathrm{Y}=140 \mathrm{~mm}$, thickness $40 \mathrm{~mm}$ ).

Cylindrical samples were subjected to uniaxial compression by a standard procedure [14], as a result of which the static Young's modulus $E=9.2 \mathrm{GPa}$ and the Poisson's ratio $v=0.21$ (average values) were determined, which corresponds to the same parameters for coals $[15,16,17]$. At each loading step an ultrasonic time-pulse method with UD2M-PN flaw detector was used to determine the velocity of longitudinal waves $V$. The processing of the obtained data by the original technique $[18,19]$ made it possible to obtain an experimental dependence

$$
V(\sigma)=A-B \exp \left(-\alpha \sigma / \sigma_{0}\right),
$$

where $\sigma$-mean normal stress, $\mathrm{A}=3041 \mathrm{~m} / \mathrm{s}, \mathrm{B}=671 \mathrm{~m} / \mathrm{s}, \alpha=0.87$ и $\sigma_{0}=3 \mathrm{MPa}$.

During main experiments, a rectangular sample was subjected to mechanical loading along the Y axis using a GT 2.0.8-2 loading machine. In this case, special gaskets $l$ were placed on the contact areas of the sample with loading plates $P_{1}$ and $P_{2}$ (Figure 1) to simulate zones with low friction. On the vertical surfaces of the plate, twelve acoustic piezoelectric transducers $S_{1}, \ldots S_{12}$ (resonant frequency $100 \mathrm{kHz}$ ) were fixed. These transducers can function as receivers or emitters. The signals were recorded by means of ADC E20-10 with a sampling rate of $5 \mathrm{MHz}$ coupled with PC.
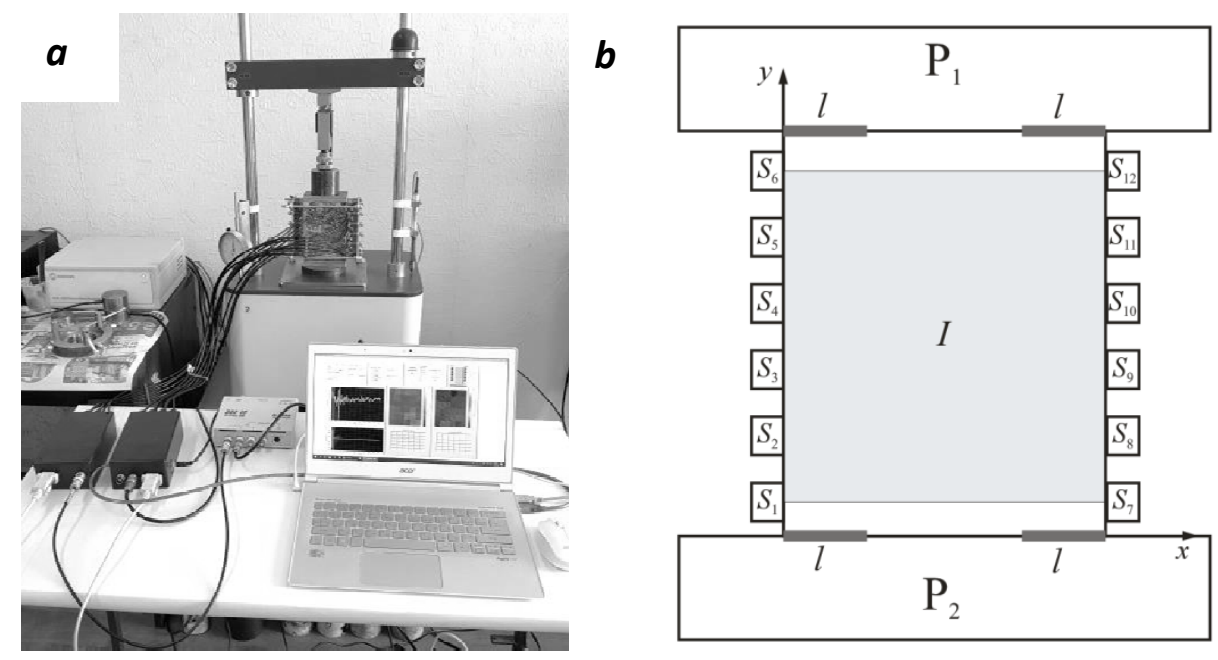

Fig. 1. General view of the laboratory setup (a) and loading scheme (b) $\left(\mathrm{P}_{1}, \mathrm{P}_{2}\right.$ - steel plates, $S_{i}$ acoustic transducers, $I$ - illuminated area, $l$ - length of reduced friction zones). 
The sample was loaded discretely with a step of $2 \mathrm{MPa}$. At each stage of loading $k$, sounding was carried out: the $S_{m}$ transducer generated a pulse, which was received by six receivers at the opposite end. The absolute accuracy of recording the first arrival of P-wave was $0.2 \mu \mathrm{s}$. On the first arrival, the time $t_{m n}^{k}$ of the path of the longitudinal wave between $S_{m}$ and $S_{n}$ was determined. Matrix $\left\{t_{m n}^{k}\right\}$ become an input data for tomography. Database $\left\{t_{m n}^{k}\right\}$ was formed as a result of two experiments:

- press plates are rigidly fastened to the sample $(l=0)$;

- at the edges of the contact surfaces "sample-plate" there are areas with low friction of length $l=25 \mathrm{~mm}$.

The values $t_{m n}^{k}$ were calculated from the accumulation of ten signals.

\section{Reconstruction of speed distribution of longitudinal waves}

Tomography of the sample was carried out using the original iterative procedure $[18,19]$, the stability of which is ensured by the expansion of the solution at intermediate steps in a specially constructed basis [20]. In Figure 1, the illumination domain $I$ is highlighted for the selected observation system $\left\{S_{m}\right\}$. Figure 2 shows the longitudinal velocity distributions $V(x, y)$ in region $I$ under different conditions of contact of the loading device with the sample and the magnitude of the vertical load $P$.
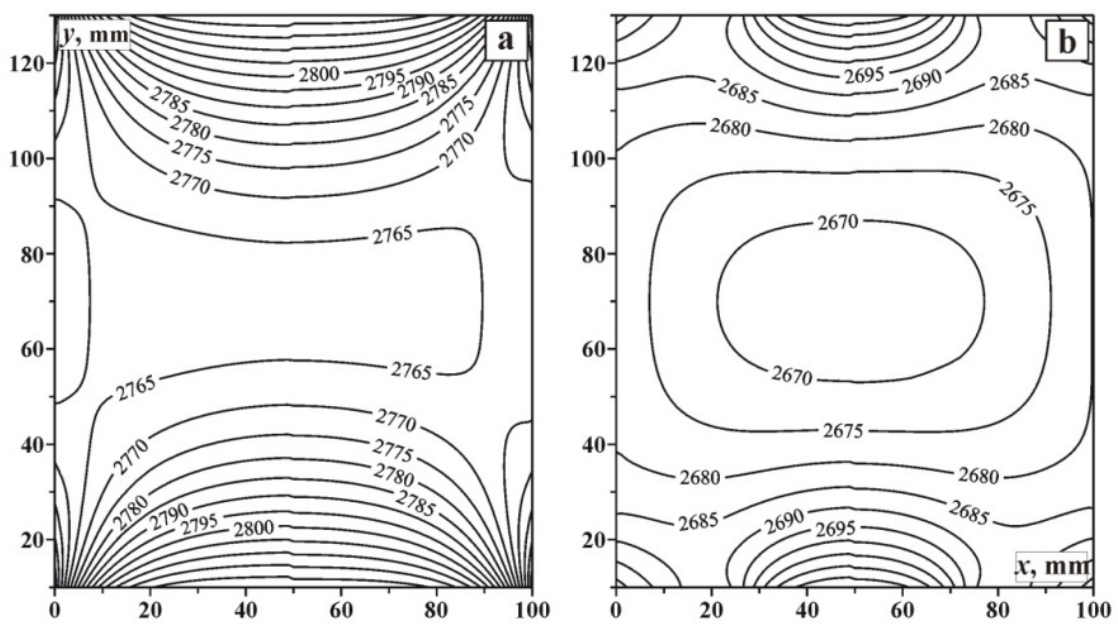

Fig. 2. Lines of the velocity level of longitudinal waves $V(\mathrm{~m} / \mathrm{s})$ in a sample reconstructed as a result of tomography: $P=6 \mathrm{MPa}, l=0$ (a); $P=6 \mathrm{MPa}, l=25 \mathrm{~mm}(\mathrm{~b})$.

The main reason for the asymmetry of isoline patterns is in chaotic arrangement of the aggregate particles in the sample matrix. As an example, Figure 3 shows the stress curves in the horizontal section of $y=y_{0}$, calculated from (1) and found by the tomography of the velocity $V$ (Figure 2 ) for different values of $P$ and contact conditions (solid lines $l=25 \mathrm{~mm}$, dashed lines $l=0$ )

$$
\Sigma(x)=\sigma\left(x, y_{0}\right)=\frac{\sigma_{0}}{\alpha} \ln \frac{B}{A-V\left(x, y_{0}\right)}
$$




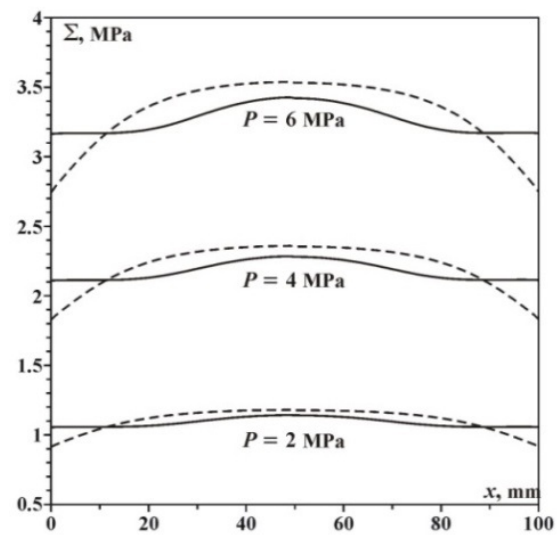

Fig. 3.Mean normal stress $\sigma$ via $x$ in the cross section $y=y_{0}\left(y_{0}=0.2 Y\right.$, positive values correspond to compression).

In experiments, the magnitude of the load was set so that the deformation of the sample occurred in an elastic regime, therefore, $\sigma$ is practically proportional to $P$. It is the dependences of $\Sigma(x)$ that are the input data for the inverse problem considered below.

\section{Determination of shear stresses on the boundaries of the sample based on the solution of the inverse problem}

We assume that on horizontal boundaries the distribution of vertical stresses is given

$$
\sigma_{y y}(x, 0)=\sigma_{y y}(x, Y)=P
$$

and according to the data of the tomography $\sigma\left(x, y_{0}\right)=\Sigma(x)$ is known. It is necessary to find shear stresses $\sigma_{x y}$ for $y=0, Y$. For this we use the method developed in [21].

Figure 4 shows the results of the solution of the inverse problem: the distribution of tangential stresses $\sigma_{x y}(x, Y)=F(x)$ at the upper boundary of the sample at different load values and contact conditions. As expected, the function $F(x-0.5 X)$ is odd, in the neighbourhood of the points $x=l$ and $x=X-l$, the concentration of stresses occurs due to a sudden change in the contact conditions of the plates with the sample.

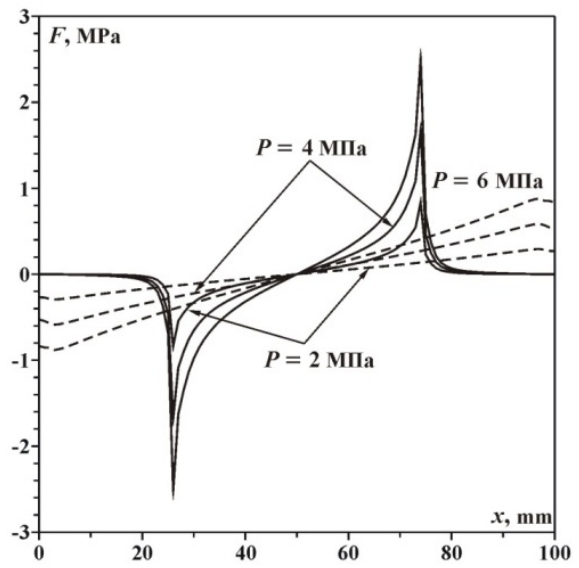

Fig. 4. The stresses $\sigma_{x y}$ at the boundary $y=0$, obtained by solving the inverse problem. Solid lines correspond to $l=25 \mathrm{~mm}$, dashed lines - to $l=0$. 


\section{Stress state of the sample at the various conditions of contact}

Let us analyse the stress field in a sample under different contact conditions on horizontal boundaries. For this, within the frames of a linear-elastic model, which includes:

equilibrium equations

$$
\sigma_{i j, j}=0
$$

Hooke's law

$$
\sigma_{i j}=\frac{E}{1+v}\left(\frac{v}{1-2 v} \varepsilon \delta_{i j}+\varepsilon_{i j}\right)
$$

and the Cauchy relation

$$
\varepsilon_{i j}=0.5\left(u_{i, j}+u_{j, i}\right) .
$$

We solve the following boundary-value problem in the domain $D=\{0 \leq x \leq X, 0 \leq y \leq Y\}$ (Figure 5)

$$
\begin{gathered}
\sigma_{x x}(0, y)=\sigma_{x y}(0, y)=\sigma_{x x}(X, y)=\sigma_{x y}(X, y)=0, \\
\sigma_{x x}(x, 0)=P \quad \sigma_{x y}(x, 0)=F(x), \\
\sigma_{x x}(x, Y)=P \quad \sigma_{x y}(x, Y)=-F(x),
\end{gathered}
$$

where $\varepsilon_{i j}$ - components of the strain tensor $(i, j=x, y), \varepsilon=\varepsilon_{x x}+\varepsilon_{y y}, u_{i}$ - displacements, summation is performed over repeated indices, and the function $F(x)$ is the result of solving the inverse problem. The system (4)-(7) was solved by the finite element method using the original code [22].

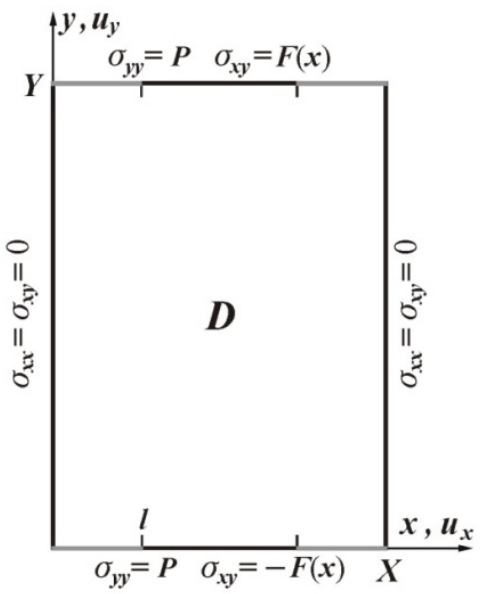

Fig. 5. Scheme of calculation domain and boundary conditions.

Figure 6 shows isolines of horizontal stresses $\sigma_{x x}$ (related to $P$ ) for $l=0$ and $l=25 \mathrm{~mm}$, respectively. It turned out that if the surface of the sample and the loading plate (in actual conditions - the coal bed and host rocks) have good adhesion, then in the central part $D$ there is an extensive zone of horizontal tensile stress. Stress in that zone is insignificant (about $0.02 P$ ) and does not exceed strength limitsfor coal even at $P=25-30 \mathrm{MPa}$ (which corresponds to lithostatic pressure at a depth of $1 \mathrm{~km}$ ).

If the edges of the horizontal boundaries are areas of slippage, then in their vicinity there arise areas of horizontal tension stress reaching $0.8 P$. These areas will be the most likely foci of destruction and sudden bursts. 

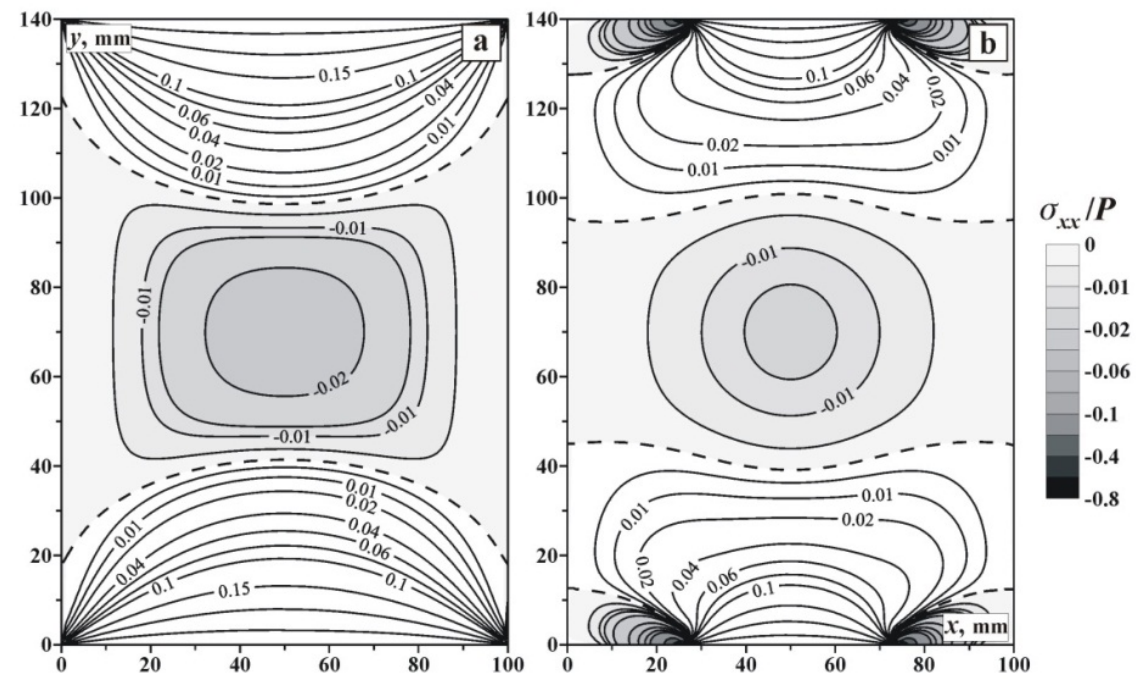

Fig. 6. Isolines of horizontal stress $\sigma_{x x}$ for different sizes of slip zones: $l=0$ (a); $l=25 \mathrm{~mm}(\mathrm{~b})$.

\section{Conclusion}

A method has been developed that makes it possible to determine the conditions at the contact of a coal seam with host rocks. It is based on the solution in the geomechanical model of the inverse boundary problem by seismic tomography data using empirical dependences of the speed of elastic waves on the stresses obtained under laboratory conditions. The method can be used to reconstruct the stress-strain state of rock mass, changing during the excavation of reserves, as well as to obtain information about the geological conditions of coal seams occurrence, necessary for the prediction of the outburst hazard.

The study was supported by the Russian Science Foundation, project no. 16-17-00029.

\section{References}

1. J. Seidle, Fundations of coalbed methane reservoir engineering. PennWell Books. 416 p. (2011).

2. V. Bondarenko, I. Kovalevska, K. Ganushevych, Progressive Technologies of Coal, Coalbed Methane, and Ores Mining. CRC Press. 534 p.

3. V.N. Zakharov, Sejsmoakusticheskoe prognozirovanie i kontrol' sostoyaniya i svojstv gornykh porod pri razrabotke ugol'nykh mestorozhdenij. M.: IGD im. A.A. Skochinskogo, 172 s. (2002).

4. L. Zhenbi, Zh. Baiting, Microseism monitoring system for coal and gas outburst// Int. J. Computer Sci. Issues. V. 9(5). N 1. P. 24-28 (2012).

5. Al Heib, M. Numerical and Geophysical Tools Applied for the Prediction of Mine Induced Seismicity in French Coalmines // Int. J. of Geosciences. V. 3(4). P. 834-846. (2012).

6. D. Palmer, High resolution seismic reflection surveys for coal // Geoexploration.. V. 24. 397-408 (1987).

7. H.Jr. Henson, J.L. Sexton, Premine study of shallow coal seams using high resolution seismic reflection methods // Geophysics. V. 56(9). P. 1494 - 1501 (1991). 
8. J. Cocker, M. Urosevic, B.A. Evans, High Resolution Seismic Survey to Assist in Mine Planning / Proceedings of Exploration 97: Fourth Decennial International Conference on Mineral Exploration. Edited by A.G. Gubins. P. 473 -476. (1997).

9. M. Khukhuudei, U. Khukhuudei, High Resolution Seismic Reflection Survey for Coal Mine: fault detection / American Geophysical Union, Fall Meeting. Abstract NS43A3856 (2014).

10. K.V. Mironov, Spravochnik geologa-ugol'shchika. M.: Nedra. 363 s. (1988).

11. A. L. Karchevsky, L. A. Nazarova, V. N. Zakharov, L. A. Nazarov, Stress state estimation in coal bed under random conditions in contact zone with enclosing rocks based on inverse problem solution. Gornyi Zhurnal. N 11. P. 37-40. (2017).

12. M.E. Everett, Near-surface applied geophysics. Cambridge University Press. 403 p. (2013).

13. W.M. Telford, L.P. Geldart, R.E. Sheriff, Applied Geophysics. $2^{\text {nd }}$ Edition. Cambridge University Press. 744 p.(1990).

14. GOST 28985-91. Metod opredeleniya deformatsionnykh kharakteristik pri odnoosnom szhatii.

15. V. L. Shkuratnik, P. V. Nikolenko, A. E. Koshelev. Stress dependence of elastic Pwave velocity and amplitude in coal specimens under varied loading conditions. Journal of Mining Science. V.52(5). P. 873-877. (2016).

16. Fiziko-tekhnicheskie svojstva uglej i gornykh porod Kuznetskogo bassejna: Spravochnik / G.G. SHtumpf, Yu.A. Ryzhkov, V.A. SHalamanov i dr. M.: Nedra,. 447 s. (1994).

17. Fizicheskie svojstva gornykh porod i poleznykh iskopaemykh (petrofizika): Spravochnik geofizika. Red. N.B.Dortman. M.: Nedra, 526 s. (1976).

18. L.A. Nazarova, V.N. Zakharov, V.L. Shkuratnik et al. Use of tomography in stressstrain analysis of coal-rock mass by solving boundary inverse problems, Procedia Engineering, P. 1048-1055. (2017).

19. L. A. Nazarova, L. A. Nazarov, M. I. Protasov. Reconstruction of 3D stress field in coal-rock mass by solving inverse problem using tomography data. Journal of Mining Science. V.52(4). P. 623-631. (2016).

20. M.J. Woodward, D. Nichols, O. Zdraveva et al. A decade of tomography // Geophysics, V.73(5). P. VE5-VE11. (2008).

21. A. L. Karchevsky. Determination of the possibility of rock burst in a coal seam. Journal of Applied and Industrial Mathematics. V. 11(4). P. 527-534. (2017).

22. L. A. Nazarova, L. A. Nazarov. Dilatancy and the formation and evolution of disintegration zones in the vicinity of heterogeneities in a rock mass. Journal of Mining Science. V.45(5). P. 411-419. (2009). 